\title{
Investment Characteristics of Natural Monopoly Companies
}

\author{
Skapa Stanislav
}

\begin{abstract}
This paper explores the possibilities of investment by private investors in natural monopoly companies. The paper analyzes the broad issue of risk measurement with focus on downside risk measurement principle. The main scientific aim is to adopt a more sophisticated and theoretically advanced statistical technique and apply them to the findings. The preferred method used for the estimation of selected characteristics and ratios was the robust statistical methods and a bootstrap method.
\end{abstract}

Key words: natural monopoly, investor, investment, downside risk.

\section{INTRODUCTION}

Natural monopoly companies lead to a variety of economic performance problems: excessive prices, production inefficiencies, costly duplication of facilities, poor service quality and they have potentially undesirable distributional impacts. In the eyes of consumers, it is the high prices and poor service quality that they most probably perceive. However, the question that arises is: what brings the investment into the natural monopoly company to investors?

\section{THEORETICAL SOLUTIONS}

\subsection{Natural monopoly}

Economists have been analyzing natural monopolies for more than 150 year. Sharkey (1982) provides an overview of the intellectual history of economic analysis of natural monopolies and he concludes that John Stuart Mill was the first to speak of natural monopolies in 1848 .

One of the main questions is how a natural monopoly should be defined. There are some characteristics which should help to understand what a natural monopoly mean.

According Thomas Farrer (1902, referenced by Sharkey, 1982) a natural monopoly is associated with supply and demand of characteristics that include:

- the product or supplied service must be essential

- the products must be non-storable

- the supplier must have a favourable production location.

Richard Ely (1937, referenced by Sharkey, 1982) added that the proportion of fixed to variable costs must be high.

Kaysen and Turner (1959, p. 191, 195-96) point out that economies of scale is a relative concept that depends on the right definition of the relevant product and geographic markets. They also argue that "ruinous competition" leading to monopoly may arise when the ratio of fixed to variable costs is high. 
Posner (1969, p.548) observed that "network effects" could lead to sub-additive costs even if the cost per customer increased as the number of customers connected to the network increased. As more subscribers are connected to a telephone network, the average cost per subscriber may rise, but it may still be less costly for a single firm to supply the network service.

Kahn (1970) refers to both economies of scale and the presence of fixed costs that are a large fraction of total costs as attributes leading to destructive competition that will in turn lead a single firm or a very small number of firms in the market in the long run.

According to (Pindyck and Rubinfeld, 2001) markets with natural monopoly characteristics are thought to lead to a variety of economic performance problems: excessive prices, production inefficiencies, costly duplication of facilities, poor service quality, and these have potentially undesirable distributional impacts.

Based on the above characteristics it is possible to identify companies as natural monopolies mainly from these sectors:

- Oil \& Gas Storage

- Electric Utilities

- Gas Utilities

- Water Utilities

- Power Producers

- Airports

- Highways \& Railways (Toll roads)

- Marine Ports \& Services

- Telecommunication

Some of the above characteristics have an impact on the financial performance of natural monopoly companies, which describes Kidokoro (1998).

\subsection{Natural Monopoly Index}

Since direct investment in natural monopoly company is not a viable option for most investors, a number of investors will choose to gain exposure to natural monopoly company using listed natural monopoly stock company and there are 3 main possibilities:

- Invest into stock company which is from natural monopoly related sector (e.g. utilities).

- Invest into stock investment fund which is specialized in natural monopoly related companies.

- Invest into special stock natural monopoly index fund or index certificate.

There is one special index covering stock companies with natural monopoly characteristics, it is Natural Monopoly Index 30 Infrastructure Global Net Return (NMXGlobal). According to Guide of index The NMX30 Infrastructure Global provides liquid and tradable exposure to 30 companies around the world which provide basic infrastructure facilities. These companies are natural monopolies with predictable and stable cash flows due to the underlying business model (long duration of concessions, goods and services provided etc.). Basic infrastructure companies have a protected market position due to their cost structure (high sunk cost and decreasing average cost). The low technology risk and inelastic demand of goods and services 
provided translate in a comparatively low correlation to other asset classes and a linkage to long term GDP growth. The NMX30 Infrastructure Global is well diversified across regions, sectors and currencies. The universe of the NMX index family is based on the following infrastructure subsectors: toll roads/bridges, airports, ports, pipeline networks (water, gas, oil) and communication networks.

This paper is analysing the risk profile and some other important characteristics (e.g. return, Sharpe ratio, Sortino ration) of NMXGlobal index compared to some well known equity indexes:

- STOXX Global Select Dividend 100 Net Return is the composite equity index covering countries in the developed markets. Companies are selected on the basis of dividend criteria and the weighting of the companies in the index is purely based on dividends.

- MSCI World Net Return Index is the composite equity index covering countries in the developed markets. The index is capitalizations weighted.

- MSCI World Value Net Return Index is the composite equity index covering countries in the developed markets. The index is value weighted. The objective of a value-weighted index is to tilt an underlying standard equity index towards stocks with lower valuations. This tilt is achieved by multiplying the market capitalization weight of each stock in the parent benchmark index with the stock's relative valuation ratio (for example, earnings to price, sales to price, book value to price, etc).

All returns are quarterly total returns (with dividends) expressed in Euros. The data are available from January 1999 until June 2011 (50 values per index). This time is not a long period due to the short time series of NMXGlobal index.

\subsection{Measurement of risk}

During historic period, problems of objectifications of risk measurement by using a concept of probability and applying statistical analysis were discussed. In 1952, two authors published the ultimate papers for financial industry, the fist was H. Markowitz (1952) who identified risk as related to the varying financial outcomes and adopted the standard deviation of the residual assets as the tool for measurement of risks. He also provided a quantitative framework for measuring the portfolio risk. The second one was A. Roy (1952) who introduced the "Safety First" criterion, which meant introduction of a downside risk measurement principle. A few years later, Markowitz (1959) gave a generalized discussion on the risk and introduced alternative measurement tools as semi-variance, expected value of loss, expected absolute deviation, probability of loss and the maximum loss. Markowitz also introduced his idea of downside-risk and suggested two types of a downside risk measurement:

- a semi-variance computed from the mean return or below-mean semi-variance (SVm)

- a semi-variance computed from a target return or below-target semi-variance (SVt).

Both measures compute a variance using only the returns below the mean return (SVm) or below a target return (SVt). Markowitz called these measures partial or semi-variances, because only a subset of the return distribution is used (see Nawrocki, 1999). 
$S V m=\frac{1}{K} \sum_{T=1}^{K} \max \left[0,\left(E-R_{T}\right)\right]^{2}$,

$S V t=\frac{1}{K} \sum_{T=1}^{K} \max \left[0,\left(t-R_{T}\right)\right]^{2}$,

where $R_{T}$ is an asset return during the time period $T, K$ is the number of observations, $t$ is the target rate of return and $E$ is an expected mean return of the asset return. A maximizing function denoted as max, indicates that the formula will square the larger of the two values i.e. 0 and $(\mathrm{E}-\mathrm{RT})$ or $(\mathrm{t}-\mathrm{RT})$. After proposing the semi-variance measure, the classical author stayed with the variance measure because it was computationally simpler. The semi-variance optimization models using a cosemivariance matrix (or semi-covariance if that is your preference) require twice the number of data inputs than the variance model. With the lack of cost-effective computer power and the fact that the variance model was already mathematically very complex in these times as it belonged to the class of quadratic programs, this was a dominant consideration in practical applications until the 1980s. It was used with the advent of the microcomputer (Nawrocki, 1999). Markowitz (1991) and this approach was also further developed in order to define a measure of downside risk.

According to findings by Kahneman and Tversky's (1979) loss aversion preferences imply that investors who dislike downside losses will demand greater compensation, in the form of higher expected returns, for holding shares with high downside risk.

Sortino and Van der Meer (1991) note that standard deviation has one major drawback. Standard deviations measure uncertainty or variability of returns but in some cases this does not match one's intuition about risks. Large positive outcomes are treated as equally risky as large negative ones. In practice, however, positive outliers should be regarded as a bonus and not as a risk. It is therefore better to look at some measure of downside risk.

\section{METHODOLOGY}

50 quarterly data per each index were obtained. It is a relatively small sample to make some strong conclusions. Due to this fact, some parametrical tests were not found suitable. Therefore some robust statistical methods and bootstrap method were used. It means that robust statistical methods aim to construct statistical procedures that are stable (robust) even when the underlying model is not perfectly satisfied by the available data set. Robust models focus on the statistical properties of the bulk of the data without being distracted by outliers, while in classical models all data equally participate in the analysis. Classical estimators that assign equal importance to all available data are highly sensitive to outliers.

Therefore, in the presence of just a few extreme losses, classical analysis can produce arbitrarily large estimates of mean, variance, and other statistics. Bassett et al. (2004) investigate the performance of portfolio return distribution using robust and quantile-based methods, and conclude that the resulting forecasts outperform those under a conventional classical analysis. Perret-Gentil and Victoria-Feser (2005) used robust estimates for mean and the covariance matrix in the mean-variance portfolio selection problem. They showed that the robust portfo- 
lio outperforms the classical one, as the outlying observations (that account for $12.5 \%$ of the data set) can have serious influence on portfolio selection under the classical approach. The same purposes, i.e. the presence of skewed distributions and extreme values, led to useing the interquartile range (by practitioner's hint for a normal distribution is approximately equal to $1,35^{*}$ standard deviation).

The bootstrap method was used with only on a small number of data. The bootstrap method was originally proposed by Efron (1979) and it is a computationally-intensive method for estimating the distribution. To use the bootstrap or any other statistical methodology effectively, one has to be aware of its limitations. The bootstrap is of a value in any situation in which the sample can serve as a surrogate for the population. If the sample is not representative of the population because the sample is too small, biased, or not selected in a random way, or its constituents are not independent, then the bootstrap based techniques fail. Canty et al. (2000) also list data outliers, inconsistency of the bootstrap method, incorrect resampling of a model, wrong or inappropriate choice of statistics, non-pivotal test statistics, nonlinearity of the test statistics, and discreteness of the resample statistics as potential sources of error. The pitfall of using the bootstrap method also shows the Terpstra and McKean (2005) and Salibian-Barrera M, and Zamar R.H. (2002).

Therefore for an index analysis there were made 10 times 2500 bootstrap samples per index that means that each index statistics and characteristic was estimated 10 times. For a "final" enumerating of statistics and characteristics the trimean was used.

\section{RESULTS AND DISCUSSION}

Firstly, it was processed an explanatory data analysis of all four indices (quarterly data), the results are shown in Table 1 . According to the descriptive data analysis one could say that medians are greater than means and trimmed means (12,5\%) except NMXGlobal (timed mean is greater than median). Comparing standard deviations to interquartile ranges/1,35 is different for NMXGlobal, the standard deviation is less than interquartile ranges/1,35 only for this index. In addition, kurtosis statistics show that the distributions have fatter tails than normally distributed variables.

Tab. 1 - Quarterly summary statistics of equity indices. Source: Own calculation

\begin{tabular}{|l|c|c|c|c|}
\hline & GlobalSD & NMXGlobal & World & WorldValue \\
\hline Count & 50 & 50 & 50 & 50 \\
\hline Average & 2,906 & 2,47 & 0,756 & 0,978 \\
\hline Median & 4,25 & 2,85 & 3,05 & 2,95 \\
\hline $12 \%$ Trimmed mean & 3,415 & 2,895 & 1,445 & 1,7325 \\
\hline Standard deviation & 9,58618 & 7,61276 & 9,42286 & 9,41341 \\
\hline Minimum & $-28,7$ & $-18,4$ & $-20,7$ & $-20,9$ \\
\hline Maximum & 22,0 & 15,6 & 23,7 & 16,3 \\
\hline Range & 50,7 & 34,0 & 44,4 & 37,2 \\
\hline
\end{tabular}




\begin{tabular}{|l|c|c|c|c|}
\hline Lower quartile & $-2,1$ & $-1,5$ & $-4,8$ & $-4,1$ \\
\hline Upper quartile & 8,4 & 9,4 & 6,4 & 7,0 \\
\hline Interquartile range & 10,5 & 10,9 & 11,2 & 11,1 \\
\hline Interquartile range/1,35 & 7,8 & 8,1 & 8,3 & 8,2 \\
\hline Stnd. Skewness & $-2,22421$ & $-1,5718$ & $-1,48131$ & $-2,01475$ \\
\hline Stnd. Kurtosis & 2,29031 & 0,228954 & 0,59373 & 0,275458 \\
\hline
\end{tabular}

Next the related Box and Whiskers plots were made and results are shown in Fig. 1.

\section{Box-and-Whisker Plot}

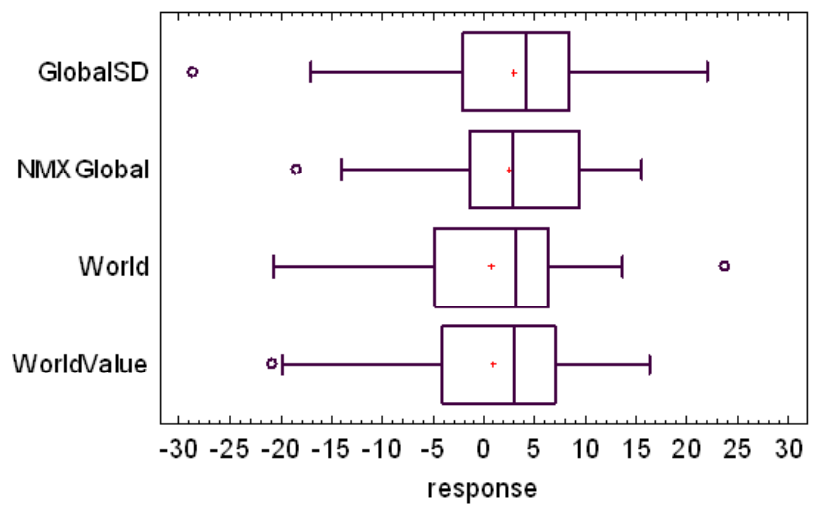

Fig. 1 - Box and Whiskers plot. Source: Own calculation

Finally annualized summary statistics of equity indices were calculated, firstly with using standard deviation and enumerating Sharpe ratio (see Table 2).

Tab. 2 - Annualized summary statistics of equity indices. Source: Own calculation

\begin{tabular}{|l|l|l|l|l|}
\hline & GlobalSD & NMXGlobal & MSCI World & \multicolumn{1}{|c|}{$\begin{array}{c}\text { MSCI World } \\
\text { Value }\end{array}$} \\
\hline Expected Return & 11,62 & 9,88 & 3,02 & 3,91 \\
\hline Standard Deviation & 19,17 & 15,22 & 18,86 & 18,83 \\
\hline Sharpe ratio+ & 0,48 & 0,48 & 0,03 & 0,07 \\
\hline
\end{tabular}

+risk free rate is set to $2,5 \%$

And secondly there were calculated estimations of annualized summary statistics of equity indices with using a bootstrap method and measure a downside deviation and other statistics (see Table 3). 
Tab. 3 - Estimated annualized summary statistics of equity indices. Source: Own calculation

\begin{tabular}{|l|l|l|l|l|}
\hline & GlobalSD & NMXGlobal & MSCI World & \multicolumn{1}{|c|}{$\begin{array}{c}\text { MSCI World } \\
\text { Value }\end{array}$} \\
\hline Expected Return & 11,06 & 9,83 & 2,59 & 3,62 \\
\hline Median & 12,13 & 10,39 & 3,44 & 4,67 \\
\hline Standard Deviation & 18,37 & 14,76 & 18,26 & 18,18 \\
\hline Downside Deviation* & 9,88 & 7,79 & 14,27 & 13,73 \\
\hline 5th percentile & $-20,76$ & $-15,12$ & $-28,18$ & $-27,43$ \\
\hline Sortino ratio* & 0,61 & 0,62 & $-0,17$ & $-0,10$ \\
\hline
\end{tabular}

*Target return is up to $5 \%$

\section{CONCLUSION}

According to obtained results in the process of data analysing of indexes there these facts were found:

- Among four indexes NMXGlobal has the best return to risk ratio (Sharpe and mainly Sortino).

- NMX Global is less volatile than the rest of indexes and has the lowest downside deviation.

- Estimated 5th percentile of the quarterly data is the least for NMXGlobal.

These NMXGlobal index characteristics are consequences of microeconomic issues of natural monopoly structure. Companies in a position of natural monopoly exhibit steady demand with stable and predictable cash flow streams. In some cases income is regulated or backed by certain types of guaranteed uptake or purchase agreements. In addition the revenue stream may be supported by "shadow tolls", government subsidies or other non-market interventions. The income stream from natural monopoly companies are often linked to inflation providing a natural inflation hedge against movements in market prices. All these facts contribute to a smaller fluctuation of index NMXGlobal in comparison with selected indices, which is the most evident when the downside deviation metrics are used.

\section{References}

1. Canty, A.J., Davison, A.C., Hinkley, D.V. \& Ventura, V. (2011). Bootstrap diagnostics. Retrieved from: http://www.stat.cmu.edu/www/cmu-stats/tr/tr726/tr726.html

2. Bassett, G., Gerber, G. \& Rocco, P. (2004). Robust strategies for quantitative investment management. New York: John Wiley and Sons.

3. Efron, B. (1979). Bootstrap methods: Another look at jackknife. Annual Statistics. 7(2), 1-26. http://dx.doi.org/10.1214/aos/1176344552

4. Kahn, A.E. (1970). The Economics of Regulation: Principles and Institutions. New York: Wiley.

5. Kahneman, D \& Tversky A. (1979). Prospect Theory: An analysis of Decision Under Risk. Econometrica, 47(3), 263-291. http://dx.doi.org/10.2307/1914185 
6. Kaysen, C. \& Turner, D. (1959). Antitrust Policy: An Economic and Legal Analysis. Cambridge: Harvard University Press.

7. Kidokoro, Y. (1998). Rate of Return Regulation and Rate Base Valuation. Regional Science and Urban Economics, 28(9), 629-654. http://dx.doi.org/10.1016/S0166-0462(98)00015-5

8. Markowitz, H.M. (1952). Portfolio Selection. Journal of Finance, 7(1), 77-91. http://dx.doi. org $/ 10.2307 / 2975974$

9. Markowitz, H.M. (1959). Portfolio Selection. New York: John Wiley and Sons.

10. Markowitz, H.M. (1991). Portfolio Selection (Second Edition). Cambridge: Basil Blackwell, Inc.

11. Nawrocki, D. A (1999). Brief History of Downside Risk Measures. Journal of Investing, 8(3), 9-25. http://dx.doi.org/10.3905/joi.1999.319365

12. Perret-Gentil, C. \& Victoria-Feser, M. (2005). Robust mean-variance portfolio selection. Tech. Rep. 140, International Center for Financial Asset Management and Engineering. Retrieved from: http://www.swissfinanceinstitute.ch/rp140.pdf

13. Pindyck, R. \& Rubinfeld, D. (2001). Microeconomics ( $5^{\text {th }}$ ed.). Upper Saddle River, N.J.: Prentice-Hall.

14. Posner, R.A. (1969). Natural Monopoly and Regulation. Stanford Law Review 21(6), 548-643. http://dx.doi.org/10.2307/1227624

15. Roy, A. D. (1952). Safety First and the Holding of Assets. Econometrica, 20(3), 431-449. http:// dx.doi.org/10.2307/1907413

16. Salibian-Barrera M. \& Zamar R.H. (2002). Bootstrapping robust estimates of regression. Annals of Statistics, 30(2), 556-582. http://dx.doi.org/10.1214/aos/1021379865

17. Sortino, F., \& Meer van der, R. (1991). Downside risk - Capturing what's at stake in investing situations. Journal of Portfolio Management, 17(4), 27-31. http://dx.doi.org/10.3905/ jpm.1991.409343

18. Sharkey W.W. (1982). The Theory of Natural Monopoly. Cambridge: Cambridge, University Press. http://dx.doi.org/10.1017/CBO9780511571817

19. Terpstra, J. T. \& McKean, J. W. (2005). Rank-based analyses of linear models using R. Journal of Statistical Software, 14. Web Site: http://www.jstatsoft.org/v14/i07

20. Guide to the LPX Equity Indices. Version 2.7. Web Site: http://www.lpx-group.com/nmx/ fileadmin/News/pdf_2007_E/NMX_Guide_to_the_Equity_Indices.pdf

\section{Contact information}

Doc. Ing. et Ing. Stanislav Škapa, Ph.D.

Brno University of Technology, Faculty of Business and Management

Koleni 4, 61200 Brno

E-mail:skapa@fbm.vutbr.cz.

JEL Classification: D18 